
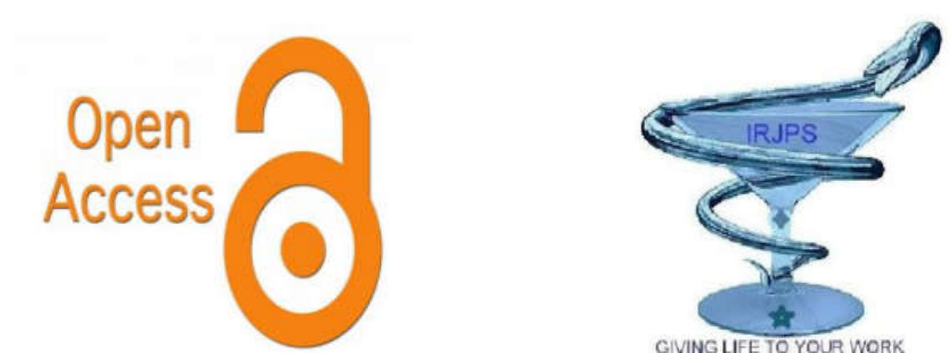

REVIEW

This is on open access article which permits unrestricted non-commercial use, provided it is properly cited. ISSN (0): 2349-5332 CODEN: IRJPHY

\title{
PHARMACEUTICAL FOLLOWING UP THE MODEL USE OF ANTI-HYPERTENSIVE AGENTS BY GENERAL MEDICINE PHYSICIANS IN PRINCE HASHEM BIN ALHUSSEIN HOSPITAL
}

\author{
Mohammed S. Alkhawaldeh*, Thamer A. Alkhawaldeh, Ali S. Alkhawaldeh， Baidaa K. Harb \\ Royal Medical Services, Jordan
}

Submitted on: 22.10.18; $\quad$ Revised on: 25.10.18; $\quad$ Accepted on: 10.11.18

\begin{abstract}
:
Background: Hypertension is the continuous increased arterial blood pressure. More than 25 antihypertensive agents are present for therapy according to patient factors. Administration of agents depends on the scale of therapy according to degree of hypertension.

Aim: To follow up the model use of antihypertensive agents in hypertensive Jordanian subjects for hypertension control.

Methods: This prospective and double blind investigation included 211 outpatient adult hypertensive participants having or not other Comorbid diseases, aged 30-70 years, of both sexes and who visited the general medicine clinic at Prince Hashim military hospital, Zarqa, JORDAN, during the period Apr 2016-Feb 2018. The data's for use of antihypertensive agents were collected from patient's medical files. The antihypertensive agents included were: Beta Blockers (BBs), Diuretics, Angiotensin Converting Enzyme Inhibitors (ACEI), Calcium Channel Blockers (CCBs), and angiotensin receptor blockers (ARBs).Antihypertensive agents use prevalence and percentage as single or multiple therapy was evaluated.

$\mathrm{Z}$ test was used to record the $\mathrm{P}$ value of age difference between two sexes. $\mathrm{P}$ value was considered statistically significant if it was less than 0.05 .

Results: The most commonly single used antihypertensive agents were Angiotensin Converting Enzyme Inhibitors (ACEI) (28.3\%). In decreasing order come: Calcium Channel Blockers (CCBs) (23.3\%), BBs (Beta Blockers)(18.3\%), angiotensin receptor blockers (ARBs) (18.3\%) and diuretics(11.7\%). Multiple therapies was administered more in $71.6 \%$ (151) of patients than single therapy which was administered in $28.4 \%$ (60) of patients. Hypertension was more in men with increasing age than women.

Conclusion: Angiotensin Converting Enzyme Inhibitors were the commonest antihypertensive used agents whether in single or multiple therapies.

Keywords: Antihypertensive agents: Beta Blockers, Diuretics, Angiotensin Converting Enzyme Inhibitors,

Corresponding Author: Md. S. Alkhawaldeh Indian Research Journal of Pharmacy and Science; 17(2018)1642-1647;

E-Mail: mohayat@hotmail.com

Journal Home Page: https://www.irjps.in

DOI: 10.21276/irjps.2018.5.3.11
\end{abstract}




\section{INTRODUCTION}

Hypertension is the continuous increased arterial blood pressure. Patients with diastolic blood pressure reading less than $90 \mathrm{~mm} \mathrm{Hg}$ and systolic blood pressure reading more than $140 \mathrm{~mm} \mathrm{Hg}$ have isolated systolic hypertension. In general, the optimal blood pressure for adults is less than $120 / 80 \mathrm{~mm} \mathrm{Hg}$. Consistent systolic blood pressure more than $140 \mathrm{~mm}$ $\mathrm{Hg}$ or a diastolic blood pressure more than $90 \mathrm{~mm} \mathrm{Hg}$ is hypertension. The number of patients complaining of increased Blood Pressure requiring therapy is as 1 billion around the globe ${ }^{1}$. High blood pressure is one of the first causing factors of Myocardial Infarction, stroke, heart failure, renal failure and retinopathy ${ }^{2}$. Hypertension is the first or the second cause for $50 \%$ of cardiovascular diseases globally ${ }^{3}$.

More than 25 antihypertensive agents are present for therapy according to patient factors. Six major classes of antihypertensives are present, as angiotensin-converting enzyme (ACE) inhibitors, angiotensin receptor blockers (ARBs), beta-blockers (BBs), calcium channel blockers (CCBs) and diuretics. Antihypertensive therapy prevents the complications of high blood pressure such as stroke, myocardial infractions, coronary heart disease and kidney failure. Irrational use of antihypertensive agents is frequent in medical practices. Nephropathy increases three fold in diabetics with a family history of hypertension. Vascular disease is frequent. Prescription pattern is the process of assessing prescription and administration of drugs in a society with attention to the resulting medical, social and economic outcome.

Regular assessment of the antihypertensive prescribing models are important because of the increasing epidemic of hypertension, increasing number of new antihypertensive agents and the increasing number of agent combinations. The prescribing model of antihypertensive agents by various physicians is not in agreement with the standard guidelines .Prescription models are an alarming cause for poor control of Hypertension, All health care providers and pharmacist must play a major role in enhancing the health care of the patients. Administration of agents depends on scales for therapy according to degree of hypertension. For primary degree hypertension, Thiazides in single or in multiple therapy are preferred. For the second degree hypertension, two agents are chosen, including one as Thiazide diuretics.

The aim of this investigation was to follow up the model use of antihypertensive agents in hypertensive Jordanian subjects for hypertension control.

\section{METHODS}

This prospective and double blind investigation included 211 outpatient adult hypertensive participants having or not other Comorbid diseases (diabetes mellitus, ischemic heart disease, chronic kidney disease and bronchial asthma), aged 30-70 years, of both sexes and who visited the general medicine clinic at Prince Hashim military hospital, Zarqa, JORDAN, during the period Apr 2016-Feb 2018 ,after obtaining approval from our local ethical and research board review committee of RMS,KHMC,JORDAN.

The antihypertensive agent's use data was collected from patient's medical files. The antihypertensive agents included were: Beta Blockers (BBs), Diuretics, Angiotensin Converting Enzyme Inhibitors (ACEI), Calcium Channel Blockers (CCBs) and angiotensin receptor blockers (ARBs) 4 (Table 1). Antihypertensive agents use prevalence and 
percentage as single or multiple therapies was evaluated. $\mathrm{Z}$ test was used to record the $\mathrm{P}$ value of age difference between two sexes. $P$ value was considered statistically significant if it was less than 0.05 .

Table 1: Available antihypertensive agents

\begin{tabular}{|c|c|}
\hline Categories of Antihypertensive agents & Available agents \\
\hline 1. Diuretics & $\begin{array}{c}\text { HYDROCHLOROTHIAZIDE } \\
\text { SPIRONOLACTONE } \\
\text { FUROSEMIDE }\end{array}$ \\
\hline 2. Angiotensin receptor blockers & $\begin{array}{c}\text { LOSARTAN } \\
\text { TELMISARTAN }\end{array}$ \\
\hline 3. $\quad$ Beta blockers & $\begin{array}{l}\text { METOPROLOL } \\
\text { ATENOLOL } \\
\text { PROPRANOLOL } \\
\text { CARVEDILOL } \\
\text { BISOPROLOL } \\
\end{array}$ \\
\hline 4. Calcium channel blockers & $\begin{array}{c}\text { AMLODIPINE } \\
\text { DILTIAZEM } \\
\text { NIFEDIPINE } \\
\text { NICARDIPINE }\end{array}$ \\
\hline 5. Angiotensin Converting Enzyme Inhibitors & ENALAPRIL \\
\hline
\end{tabular}

\section{RESULTS}

159 patients $(75.4 \%)$ were men and 52 patients $(24.6 \%)$ were women. Median age of men was 53.2 years and of women was 61.4 years. The men: women ratio was 3.05:1. 115 patients $(54.5 \%)$ were obese with men and women obesity proportion as
18.95\% (40 Men) and 35.5\% (75 women) (Table

$2)$. The most increased number of hypertensive men patients of $72(34.1 \%)$ was aged $40-60$ years and the most increased number of hypertensive women patients of 25 (11.8\%) was aged more 61-70 years( $\mathrm{P}<0.05$ ) (Table II).

Table 2: Characteristic details of all patients

\begin{tabular}{|c|c|c|c|c|c|c|}
\hline \multicolumn{7}{|c|}{$\mathrm{n}=\mathbf{2 1 1}$} \\
\hline SEX & \multicolumn{3}{|c|}{ M: 159(75.4\%) } & \multicolumn{3}{|c|}{$F: 52(24.6 \%)$} \\
\hline Average Age & \multicolumn{3}{|c|}{53.2} & \multicolumn{3}{|c|}{61.4} \\
\hline AGE(yr) & $30-39 \mathrm{yr}$ & $40-60 \mathrm{yr}$ & $61-70 \mathrm{yr}$ & $30-39 \mathrm{yr}$ & $41-60 \mathrm{yr}$ & $61-70 \mathrm{yr}$ \\
\hline & $25(11.8 \%)$ & $72(34.1 \%)$ & $62(29.4 \%)$ & $10(4.7 \%)$ & $17(8.05 \%)$ & $25(11.8 \%)$ \\
\hline \multicolumn{7}{|l|}{$\begin{array}{c}\text { Co-morbidity } \\
(n=69)\end{array}$} \\
\hline DM & \multicolumn{3}{|c|}{23} & \multicolumn{3}{|c|}{13} \\
\hline IHD & \multicolumn{3}{|c|}{6} & \multicolumn{3}{|c|}{4} \\
\hline CKD & \multicolumn{3}{|c|}{14} & \multicolumn{3}{|c|}{4} \\
\hline $\mathbf{B A}$ & \multicolumn{3}{|c|}{1} & \multicolumn{3}{|c|}{4} \\
\hline $\operatorname{Obese}(n=115)$ & \multicolumn{3}{|c|}{$40(18.95 \%)$} & \multicolumn{3}{|c|}{$75(35.5 \%)$} \\
\hline
\end{tabular}

$69(32.7 \%)$ hypertensive patients had other comorbid diseases, 36 (17.1\%) patients were diabetics, $10(4.7 \%)$ patients were with ischemic heart disease,
18 (8.5) patients were with renal disease and $5(2.4 \%)$ patients were with bronchial asthma (Table 3). 
Table 3: Single antihypertensive therapy

\begin{tabular}{|c|c|}
\hline Category & Number (\%) \\
\hline ACEIs & $17(28.3)$ \\
\hline CCBs & $14(23.3)$ \\
\hline BBs & $11(18.3)$ \\
\hline ARBs & $11(18.3)$ \\
\hline Diuretics & $7(11.7)$ \\
\hline
\end{tabular}

$60(28.4 \%)$ patients were administered single therapy (Table III) and $151 \quad(71.6 \%)$ patients were administered multiple therapy $(\mathrm{P}<0.05)$ (Table IV) with $105(69.5 \%)$ patients on 2 antihypertensive agents therapy, $40 \quad(26.5 \%)$ patients on 3 antihypertensive agents therapy and 6 (3.97\%) patients on 4 antihypertensive agents therapy. Of the single therapy model, antihypertensives percentages were: ACEIs $28.3 \%$, then by CCBs $23.3 \%$, BBs 18.7\%, ARBs $18.3 \%$ and diuretics $11.7 \%$.Table III. The most commonly used 2 agents model was CCB with BB (25.2\%). The most commonly used 3 agents model was ACEI or ARB with BB and Diuretic (5.96\%).Table 4. Patient compliance to the therapy was moderate and was better in women than men.

Table 4: Multiple antihypertensive therapies

\begin{tabular}{|c|c|}
\hline Combinations & Number (\%) \\
\hline 2 agent model & $105(69.5)$ \\
\hline CCB+BB & $38(25.2)$ \\
\hline ARB+DIURETIC & $9(5.96)$ \\
\hline ACEI+DIURETIC & $9(5.96)$ \\
\hline ACEI+CCB & $6(3.97)$ \\
\hline ARB+CCB & $6(3.97)$ \\
\hline ACEI+BB & $9(5.96)$ \\
\hline CCB+DIURETIC & $28(18.5)$ \\
\hline 3 agent model & $39(25.8)$ \\
\hline ACEI+BB+CCB & $4(2.6)$ \\
\hline ARB+BB+CCB & $4(2.6)$ \\
\hline ACEI+BB+DIURETIC & $9(5.96)$ \\
\hline ARB+BB+DIURETIC & $9(5.96)$ \\
\hline ACEI+CCB+DIURETIC & $7(4.6)$ \\
\hline ARB+CCB+DIURETIC & $6(3.97)$ \\
\hline 4 agent model & $7(4.6)$ \\
\hline ARB+BB+CCB+DIURETIC & $3(1.98)$ \\
\hline ACEI+BB+CCB+DIURETIC & $4(2.6)$ \\
\hline
\end{tabular}

\section{DISCUSSION}

Hypertension is a public health condition of $4.5 \%$ of worldwide disease. Incidence will increase from $26.4 \%$ in 2000 to $29.2 \%$ in 2025 . Adverse results may be avoided by reducing blood pressure efficiently. Beginning long term rational antihypertensive management with regular follow up is crucial.

Different antihypertensive of various pharmacological groups are present such as 
Angiotensin Converting En-zyme inhibitors, Beta Blockers, Angiotensin Receptor Blockers, Calcium Channel Blockers, Diuretics, Alpha adrenergic blockers and central sympatholytics. Selection of group for a patient modifies at short periods due to efficiency, adverse effects, cost and newer agents. Advices of management protocols may decrease practice variability, cost and enhance rational pharmacotherapy and increasing of antihypertensive treatment.

The 7th report of Joint National Committee recommends the administration of thiazides only or with other groups in uncomplicated essential hypertension. High risk states are indication for management with ACE inhibitors, ARBs, Beta blockers or CCBs. For BP more than 20/10 mm of $\mathrm{Hg}$ above aimed BP, two agents is recommended with one a thiazide diuretic.

The incidence of hypertension relies on ethnicity, genetic, environmental and physiological factors. Our investigation showed that hypertension is more common in men than in women by $43 \%$, with earlier onset of hypertension in men than in women, similar to previous investigations 5,6 , and not similar to others $^{7-9}$ who demonstrated more incidence of hypertension in women than in men. Our investigation found that hypertension is more frequent in old aged patients. This investigation stated that most commonly used antihypertensive agents are ACEIs. The administration of thiazides for the control of early degree hypertension only or with other agents was recommended earlier ${ }^{10}$. Control of primary hypertension (degree I [BP more than 20/10 $\mathrm{mm}$ of $\mathrm{Hg}$ than the normal pressure] must use thiazides, but ARBs, ACEIs, CCBs or BBs only or with others can be used ${ }^{11}$. For degree II [B.P more than $40 / 20 \mathrm{~mm}$ of $\mathrm{Hg}$ than the normal pressure] hypertension two agents multiple therapies, of which one as thiazides must be used. Of the two agent's model, CCBs with BBs is the most common model (26.26\%), and ACEIs or ARBs with BBs and diuretics was the most common three agent's model $(12.12 \%)$.

Globally the incidence of hypertension is higher in urban than in rural regions and it increases with age. Most women demonstrated an earlier onset of hypertension than men. The most important objective of antihypertensives is to avoid hypertension induced morbidity, mortality and complications. As antihypertensives are needed lifelong, the adverse effects, outcome of life and cost of agents are also important issues. Therapy of choice for early stage, uncomplicated, essential hypertension must be thiazides. Thiazides are used most commonly alone or with other agents. ARB's are the most commonly used group in hypertensive diabetics and asthmatics as angiotensin antagonism can reduce the onset \& progression of microvascular complications of hypertension and diabetes mellitus. More than half of patients worldwide use two or more antihypertensive drugs, to enhance patient compliance and decrease treatment costs.

Limitation of our study is the shortage of detailed patient files for recommending the used agents according to stage of hypertension, complications and past agent treatment.

\section{CONCLUSION}

Hypertension is more common in men than in women in JORDAN, with its incidence increasing with age. ACEIs are the most common used agents only or with other antihypertensive drug. 


\section{REFERENCES}

1. Ramadevi MND, Bibek DB, Ramesh C. Prospective study on prescribing patterns of antihypertensive drugs. World journal of pharmaceutical research 2018;7(1):646-662.

2. Bajaj JK, Sood M, Singh SJ,et al. Prescription patterns of antihypertensive drugs and adherence to JNC VII guidelines in a tertiary care hospital. International Journal of Medical and Clinical Research. 2012; 3, Issue 2:118-120.

3. Sivasakthi R, Sam S, Nithiyan,et al. Assessment of Prescribing Pattern for Hypertension and Comparison with JNC-8 Guidelines-Proposed Intervention by Clinical Pharmacist. J Young Pharm, 2016; 8(2): 133-135.

4. BrahmankarDM,Sunil B. 2009. JaiswalBiopharmaceutics and Pharmacokinetics. 2nd Edn.,pp: 378.

5. Noah J, Narasinga R, Laxmi TP. A review on prescribing patterns of antihypertensive drugs. Bio med Clinical Hypertension, 2016; 22(7): 1-8.

6. Fedila S, Tesfaye G. Assessment of prescribing, dispensing, and patient use pattern of antihypertensive drugs for patients attending outpatient department of hiwot Fana specialized University hospital, harar, eastern Ethiopia. Drug Design, Development and Therapy, 2015; 9: 519-23.

7. Johan PJ, Manimekalai K, Velvizhy $\mathrm{R}$ .Pattern of antihypertensive drug utilization in a tertiary care hospital. International Journal of Pharma and Bio Sciences, 2015; 6(4): $759-64$.

8. Ikunaiye NY, MaduSJ,YakubuSI,et al. Prescribing pattern of antihypertensives at a tertiary healthcare facility in north eastern Nigeria. International journal of pharmacy, 2015; 5(1): 59-64.

9. Manohar M, Bende, ChetnaA,et al. Satpute. Evaluation of prescription pattern and medication adherence of antihypertensive drugs in stage 1 essential hypertensive patients at ruraltertiary care teaching hospital of central India Chetan S. Urade, International Journal of Pharmacological Research.2016; 6(9): PAGE No. .

10. Amruth RV, Ashesh G, SumitG,et al. prescribing pattern of antihypertensive drugs and cost analysis in a tertiary care teaching hospital world journal of pharmacy and pharmaceutical sciences, 2015; 4(5): 958-76.

11. Krishna M M, Arif K, Akalanka D, et al. Prescription Pattern of Anti-Hypertensive Drugs in Adherence to JNC- 7 Guidelines. American Journal of Pharmacology and Toxicology, 2015, 10 (1): 27.31 